
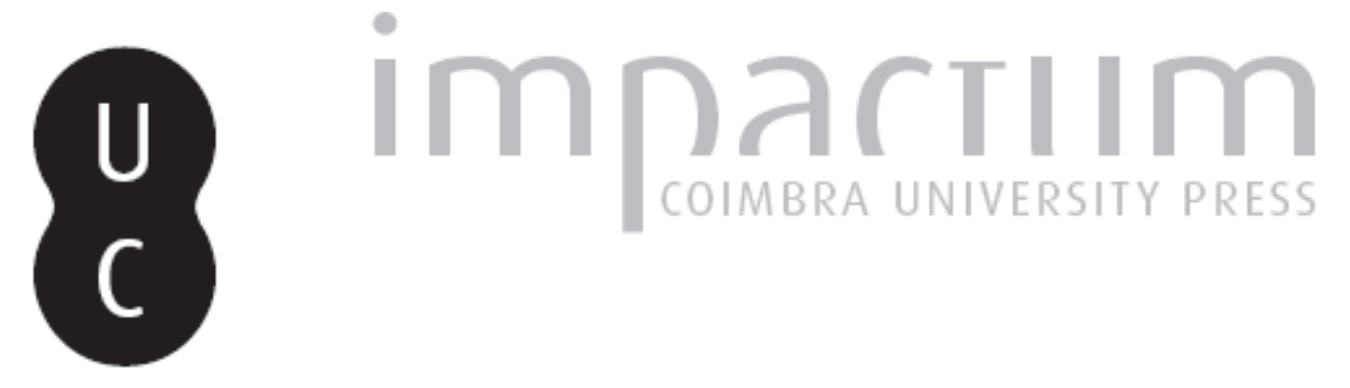

\title{
O legado do ensino moderno na Escola de Coimbra: experiências pedagógicas nas Escolas do Porto e de Lisboa
}

\author{
Autor(es): $\quad$ Moniz, Gonçalo Canto
}

Publicado por: Editorial do Departamento de Arquitetura

URL persistente:

URI:http://hdl.handle.net/10316.2/37326

DOI:

DOI:http://dx.doi.org/10.14195/1647-8681_3_11

Accessed : $\quad$ 26-Apr-2023 11:17:47

A navegação consulta e descarregamento dos títulos inseridos nas Bibliotecas Digitais UC Digitalis, UC Pombalina e UC Impactum, pressupõem a aceitação plena e sem reservas dos Termos e Condições de Uso destas Bibliotecas Digitais, disponíveis em https://digitalis.uc.pt/pt-pt/termos.

Conforme exposto nos referidos Termos e Condições de Uso, o descarregamento de títulos de acesso restrito requer uma licença válida de autorização devendo o utilizador aceder ao(s) documento(s) a partir de um endereço de IP da instituição detentora da supramencionada licença.

Ao utilizador é apenas permitido o descarregamento para uso pessoal, pelo que o emprego do(s) título(s) descarregado(s) para outro fim, designadamente comercial, carece de autorização do respetivo autor ou editor da obra.

Na medida em que todas as obras da UC Digitalis se encontram protegidas pelo Código do Direito de Autor e Direitos Conexos e demais legislação aplicável, toda a cópia, parcial ou total, deste documento, nos casos em que é legalmente admitida, deverá conter ou fazer-se acompanhar por este aviso.

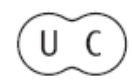




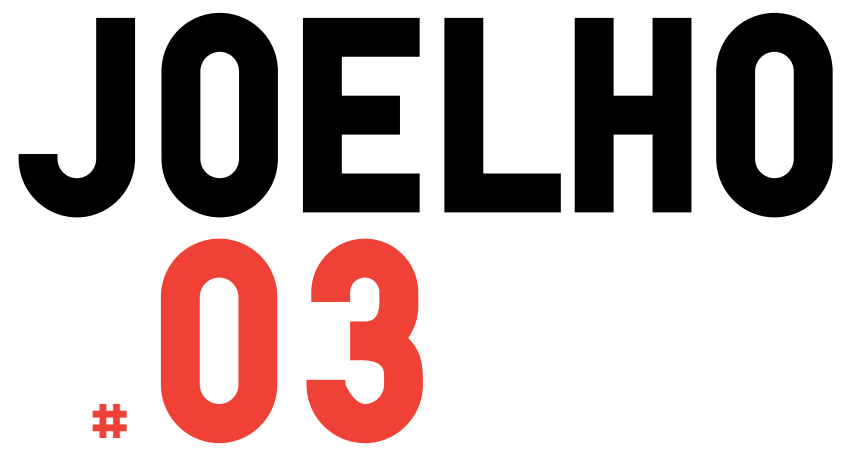

\section{VIAGEM-MEMÓRIAS: APRENDIZAGENS DE ARQUITECTURA}

Coordenação:

Alexandre Alves Costa

Domingos Tavares

Exposição Viagem

Exposição Memórias

Luis Mansilla

Alexandre Alves Costa

Domingos Tavares

SCA FoL DiNG
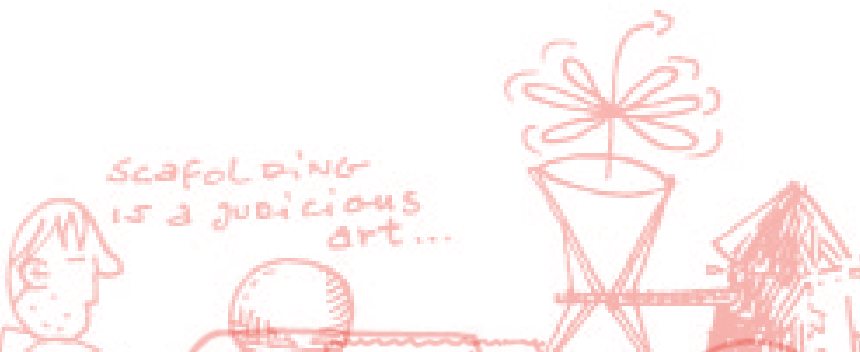

Jorge Figueira

José Miguel Rodrigues

José António Bandeirinha José Fernando Gonçalves

Paulo Providência

Gonçalo Canto Moniz Armando Rabaça

Patrícia Miguel

Bruno Gil

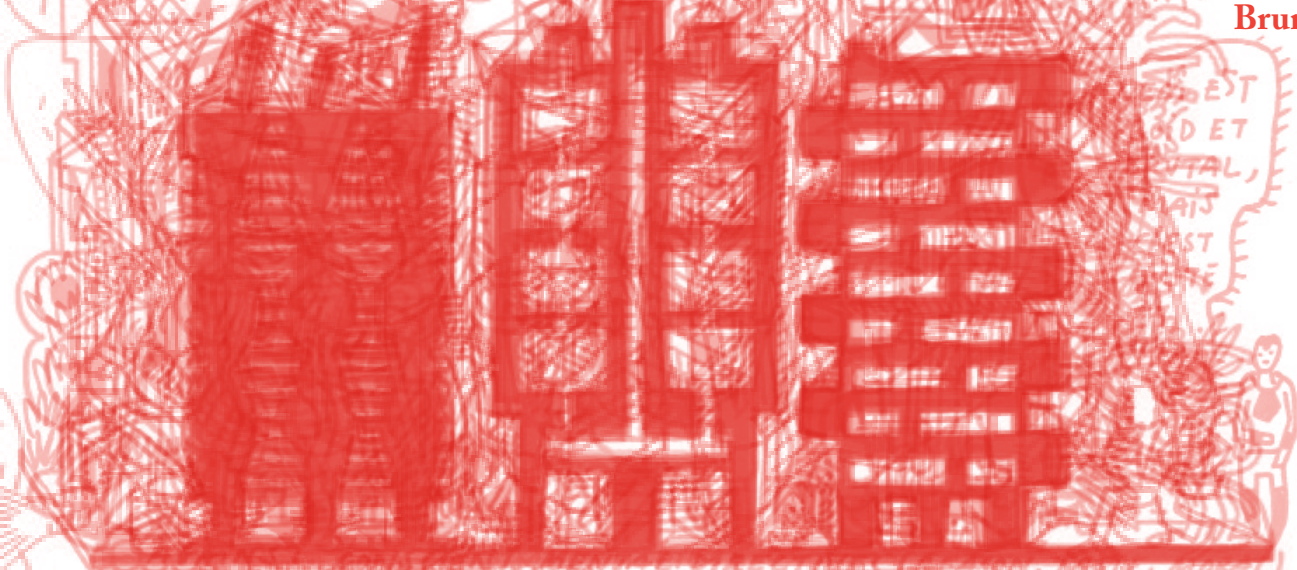

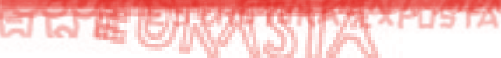


Gonçalo Canto Moniz

$O$ legado do ensino moderno na Eiscola de Coimbra: experiências pedagógicas nas Escolas do Porto e de İisboa 


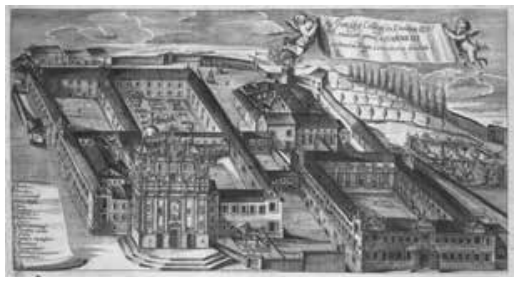

1. Colégio das Artes, gravura 1732

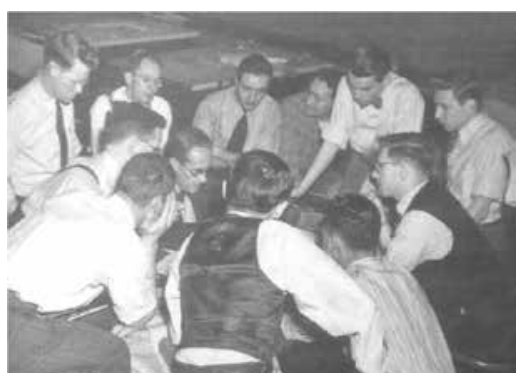

2. Walter Gropius e os estudantes de Harvard, 1937-52. Harvard University Archives.
A Escola de Coimbra nasce de uma plataforma de entendimento entre as duas vertentes pedagógicas fundadas na Escola do Porto e na Escola de Lisboa ao longo do século xx. Refundada em 1989, um ano após a sua abertura ${ }^{1}$ por um conjunto de professores do Porto e de Lisboa, Coimbra é hoje depositária do legado comum construído nas duas escolas centenárias através de caminhos distintos e por vezes contraditórios.

Deste legado, consideramos que o debate sobre o ensino moderno gerou um conjunto de experiências pedagógicas entre 1931 e 1970, que ainda hoje constituem uma espécie de ADN da formação do arquitecto. É também neste período, que se formam grande parte dos professores do Porto (Fernando Távora, Alexandre Alves Costa, Domingos Tavares) e de Lisboa (Raul Hestnes Ferreira, Manuel Tainha, Gonçalo Byrne, Vítor Figueiredo) que se encontraram em Coimbra para construir o terceiro curso público de Arquitectura. Propomos, assim, conhecer este legado moderno para melhor compreender as fundações do programa pedagógico projectado colectivamente e quotidianamente para a Escola de Coimbra.

Considerando a especificidade de curso de Coimbra (Costa, 2012, p.16-26) interessa explorar no referido legado algumas questões interrelacionadas que serão retomadas em Coimbra: primeiro, o fim do sistema beaux-arts e o problema da universidade; segundo: o debate entre o ensino artístico e o ensino científico; terceiro, a relação entre a teoria e a prática.

\section{Ensino Beaux-Arts versus Ensino Moderno}

O "Ensino Moderno da Arquitectura" (Moniz, 2011) resulta do processo de transformação do ensino Beaux-Arts, que ocorreu nas escolas de arquitectura portuguesas e internacionais. Se o ensino Beaux-Arts foi amplamente caracterizado a partir da actividade pedagógica desenvolvida na École des Beaux-Arts de Paris e na sua internacionalização e generalização, o mesmo não aconteceu com o ensino moderno.

Pelo contrário, durante o movimento moderno, diversas escolas experimentaram outras metodologias de ensino que permitissem formar o arquitecto moderno ou simplesmente prolongaram o sistema beaux-arts, admitindo o moderno como estilo. Deste conjunto alargado, consideramos que Walter Gropius foi o arquitecto e professor que ao longo deste período, se empenhou na construção de um novo paradigma de ensino para suceder ao Beaux-Arts. Este paradigma, caracterizado genericamente pela sua condição experimental, democrática e humanista, foi sendo construído nos três palcos de actuação de Gropius: a Bauhaus (1919-1926), Harvard (1937-1952) e os CIAM (1949-1953).

Para o contexto português, a Bauhaus constitui fundamentalmente um modelo arquitectónico, enquanto as propostas para a escola de Harvard serão o verdadeiro modelo pedagógico, sendo integradas tanto 
na actuação de Carlos Ramos na Escola de Belas Artes do Porto (EBAP), como na construção da Reforma de 1950, pelos professores de Arquitectura de ambas as Escolas portuguesas. Carlos Ramos assumiu esta filiação ao traduzir para português o texto matriz do pensamento pedagógico gropiano, "Plano para um ensino da Arquitectura" (Gropius, 1950).

Se as propostas pedagógicas de Gropius são conscientemente assumidas na década de 50, nas duas escolas, o debate entre o ensino moderno e o Beaux-Arts, inicia-se em 1931. Nesta data, os professores do Porto e de Lisboa fixam o ensino Beaux-Arts no plano de estudos da Reforma do Ensino Artístico, seguindo as propostas de José Marques da Silva, professor e director da EBAP. O modelo parisiense da École des Beaux-Arts é finalmente adoptado com a divisão entre curso especial e curso superior, sendo o primeiro dedicado ao estudo do clássico através do desenho e da história e o segundo, centrado no projecto através do método dos concursos de emulação.

No ano seguinte, 1932, abre o concurso para professor de Arquitectura da Escola de Belas-Artes de Lisboa (EBAL). Estes mesmos professores, perante quatro candidatos "modernistas", escolhem Cristino da Silva, que tinha filiação Beaux-Arts, e preterem a proposta de uma "educação colectiva" apresentada por Carlos Ramos na memória elucidativa do projecto para um Palácio para a Academia Nacional de Belas-Artes (Ramos, 1935, p.36). Esta decisão tem duas consequências. Num primeiro momento, Cristino da Silva consolida em Lisboa o ensino Beaux-Arts, seguindo a tradição de Paris e de mestre José Luis Monteiro. Num segundo momento, Carlos Ramos será convidado a substituir Marques da Silva no Porto, em 1940, e assim implementar a sua proposta de um ensino moderno. Assim, o concurso para professor da EBAL marcará os destinos das duas Escolas até 1950, ano em que é aprovada uma nova reforma do ensino.

Nas escolas, Cristino da Silva em Lisboa e Marques da Silva no Porto, conciliaram a formação clássica baseada no desenho das cinco ordens, com os concursos de emulação que exercitavam a competência artística dos alunos, formando assim um arquitecto artista. Esta formação admitia que os trabalhos recorressem ao estilo moderno, mas não utilizava métodos de ensino e de projecto modernos. A formação Beaux-Arts proponha uma maneira de pensar baseada na relação entre as regras de composição, a racionalidade do programa e o carácter da encomenda que promovia o ecletismo.

Os projectos de Marques da Silva para a EBAP reflectem esta atitude porque colocam no centro da composição a Sala do Antigo, uma galeria dos modelos clássicos. Esta formação poderá explicar uma certa fragilidade das propostas modernas dos arquitectos no final da década de 30, como também a sua adesão ao período nacionalista iniciado na década de 40 com a Exposição do Duplo Centenário.

O Ensino Moderno chega às escolas de arquitectura portuguesa através das ciências da educação, centrada nos pedagogos como John

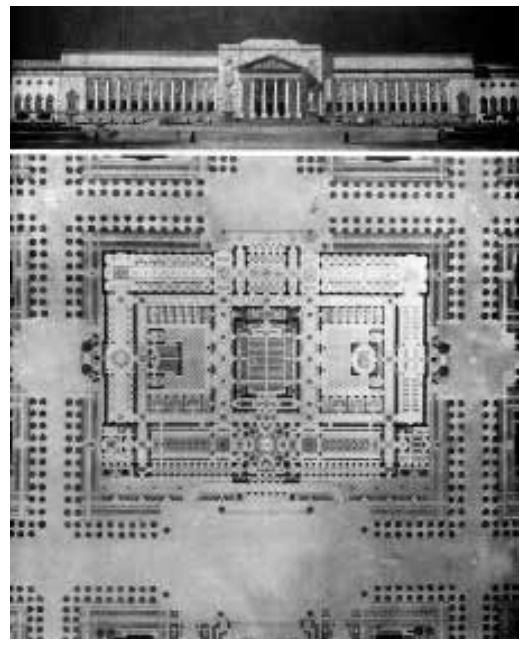

3. Cristino da Silva, Projecto para Uma Academia de Belas-Artes, Planta e Alçado, Concurso para professor da 4. ${ }^{a}$ cadeira, Prova de Composição, 1932. In Luís Cristino da Silva, A sede da Academia Nacional de Belas-Artes ... Lisboa: Academia Nacional de Belas Artes, 1973, 37.

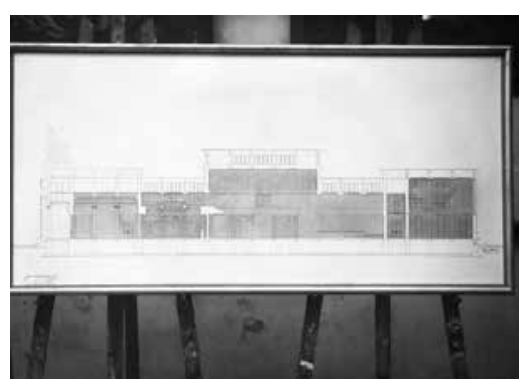

4. Carlos Ramos, Palácio para a Academia Nacional de Belas-Artes, Concurso para professor da 4. ${ }^{a}$ cadeira, Prova de Composição, 24 Agosto 1933. Arquivo FCG, Espólio Mário Novais.

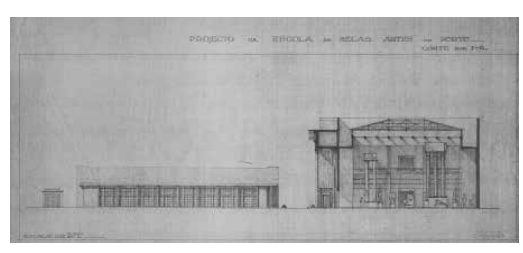

5. José Marques da Silva, Projecto da Escola de Belas Artes do Porto, Corte, 2 de Maio de 1935. Arquivo FIMS, IMS-0154. 
Dewey, Ortega y Gasset, António Sérgio e Orlando Ribeiro e, depois, através da cultura arquitectónica, nomeadamente pela ação de Walter Gropius, que já referimos e pelo CIAM, onde tentou construir, com Ernesto Rogers, uma Carta da Educação, à semelhança da Carta de Atenas.

Deste conjunto de autores de áreas e geografias distintas, podemos considerar que de facto a matriz da pedagogia está no pensamento de John Dewey, e na sua máxima "aprender fazendo" (Dewey, 1959, p. 204) que constitui um elogio ao experimentalismo e à educação democrática centrada no desenvolvimento do aluno.

Se estas ideias estão presentes no debate sobre a educação em Portugal (Cf. Tavares, 1933, p.9) será Walter Gropius a transformar e aplicar este discurso à Arquitectura ao apontar treze ideias, em "Tópicos para a discussão sobre o ensino da arquitectura" (Gropius, 1951, p.14-15). Esta discussão começa verdadeiramente nos CIAM do pósguerra com a criação, em 1947, da Comissão de Educação, apoiada por Sigfried Giedion e Ernesto Rogers e com a divulgação do seu projecto pedagógico pelo número monográfico da L'Architecture d'aujourd'hui Gropius et son École, the spread of na idea (Gropius, 1950). O impacto deste debate nas escolas portuguesas dá origem não só à tradução do texto de Gropius por Carlos Ramos, como também às reportagens da revista Arquitectura sobre a comissão de Educação dos CIAM.

Este debate é não só incorporado nas escolas, como também pelos arquitectos que começam a exigir um ensino que forme o arquitecto moderno. No âmbito nacional, o debate desenvolve-se na revista Arquitectura, com os textos de Francisco Keil do Amaral (1947), no Congresso Nacional dos Arquitectos de 1948, no Congresso da UIA de Lisboa, em 1953, e ainda na Subcomissão Arquitectura para a Reforma do Ensino Artístico, de 1949, que vão dar origem, primeiro, à Reforma de 1950 e, depois, à sua regulamentação em 1957.

A transformação política e ideológica do Estado Novo, em direcção à industrialização, vai permitir e até apoiar a transformação do perfil do arquitecto, passando do artista ao técnico. Neste processo, o momento mais significativo é desenvolvido dentro da Subcomissão de Arquitectura porque vai gerar um certo concenso entre todos os professores de arquitectura sobre a nova orientação do ensino: abandonar o sistema de concursos, reivindicar uma formação mais técnica e científica, defender a especialização, estimular os métodos de trabalho de grupo e promover a "comunhão entre professores e alunos", como refere o relatório (Subcomissão de Arquitectura, 1949).

Estes debates enquadram o quotidiano nos cursos de arquitectura das duas escolas, a partir do qual é possível compreender que sob o mesmo plano de estudos e as mesmas regras de funcionamento, foi possível construir processos de ensino distintos devido à acção do director, dos professores e dos alunos.

No Porto, consideramos que o processo de transformação do ensino se inicia em 1940 com a saída de José Marques da Silva de professor 
e de director, por atingir o limite de idade para leccionar. Esta saída permite ao novo director, o historiador Arão de Lacerda, consolidar o corpo docente ao renovar as cadeiras de Arquitectura e a de Construção. A escolha de Carlos Ramos para Arquitectura e de Rogério de Azevedo para a Construção possibilitou que Ramos transformasse o ensino da Arquitectura e que Rogério desse continuidade ao ensino da Construção, onde se aprendiam as Ordens Clássicas. O confronto entre estes dois professores, Ramos e Rogério, esteve sempre presente na Escola inibindo a integração plena do ensino moderno. No entanto, tanto o professor de Arquitectura, como os próprios directores, Arão de Lacerda, Joaquim Lopes e Carlos Ramos, a partir de 1952, apoiaram sempre as propostas para a cadeira de Arquitectura e para uma certa democratização da vida na Escola.

A entrada de novos professores em 1945 com o curso de Urbanismo e depois a entrada dos novos assistentes de Arquitectura foi talvez o maior contributo para estas transformações, que se reflectiu na pluralidade de métodos de ensino e na diversidade de abordagens ao problema da Arquitectura e da Cidade. Neste sentido, tanto a cadeira de Arquitectura como a de Urbanismo (Urbanologia e Projecto e Obras de Urbanização) possibilitaram o desenvolvimento de uma escola moderna num currículo beaux-arts, o que demonstra também a flexibilidade deste sistema.

A modernização do ensino não passou somente pela ação dos professores e directores, mas principalmente pela atitude dos alunos na contestação aos métodos de ensino, na reivindicação de professores, na organização de acções culturais e numa acção associativa que integrou os debates na universidade. A publicação do GEBAP (Grupo de Estudantes da ESBAP) foi um dos momentos mais relevantes da contestação estudantil, não só porque tinha objectivos pedagógicos, mas também porque integrava contestação política, com o apoio do MUD Juvenil. O GEBAP foi também um ensaio para a criação da Associação de Estudantes da ESBAP especialmente dinâmica nos momentos de crise académica: 1956, 1962 e 1969.

No Porto, o ensino moderno conviveu com o ensino Beaux-Arts e fundamentalmente com uma tradição humanista que colocava o aluno no centro do processo de aprendizgem. Vitrúvio, apresentado por Carlos Ramos aos alunos no primeiro dia de aulas, deveria orientar a formação ética do arquitecto enquanto as exposições, as palestras, e os concursos para a Bienal de São Paulo ou para a UIA deveria orientar a sua formação cultural.

Este ambiente foi formalizado no plano dos pavilhões da escola, desenvolvido pelos alunos na disciplina de Composição de Arquitectura de 1945-46 e concretizado entre 1949 e 1962 com a construção dos pavilhões de Desenho, Pintura e Escultura, Arquitectura e Exposições e, por fim, na Aula Magna e Edifício Principal. Deste modo, o ensino moderno foi instalado em espaços modernos através de um plano aberto, em permanente actualização, um "espaço de liberdade".
II I. I. I I I

6. Fernando Távora, [Uma praça], Planta e Perspectiva, [1946-07-29], Concurso de Composição Decorativa, EBAP, 1945-46, Professor Carlos Ramos. Arquivo FIMS. Espólio FT.

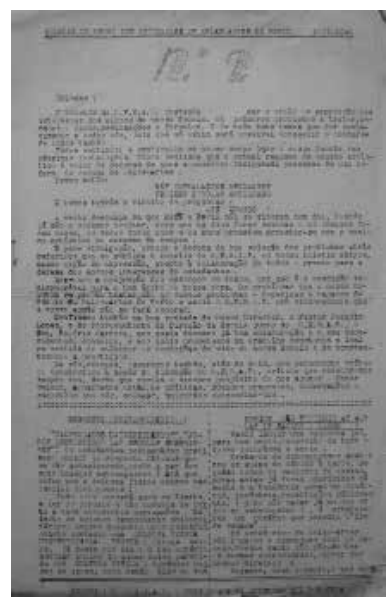

7. GEBAP, Boletim do Grupo de Estudantes das Belas-Artes do Porto, 2, 7-II-1946, 1. Arquivo CDUA-FAUP: ADM-018.

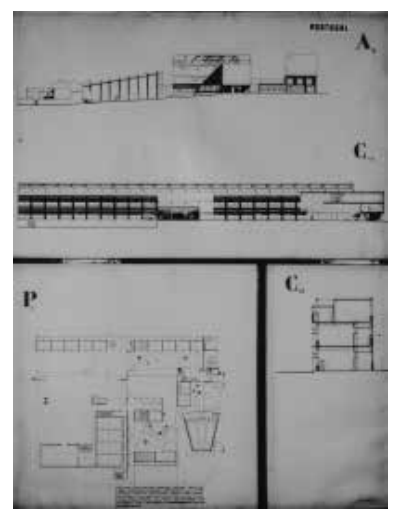

8. Luís Praça, "Um Centro Escolar", I Concurso Internacional de Emulação da UIA, Concurso de Grande Composição, EBAP, 1951-52, Professor Carlos Ramos, Assistente Mário Bonito.

Arquivo FCG. 


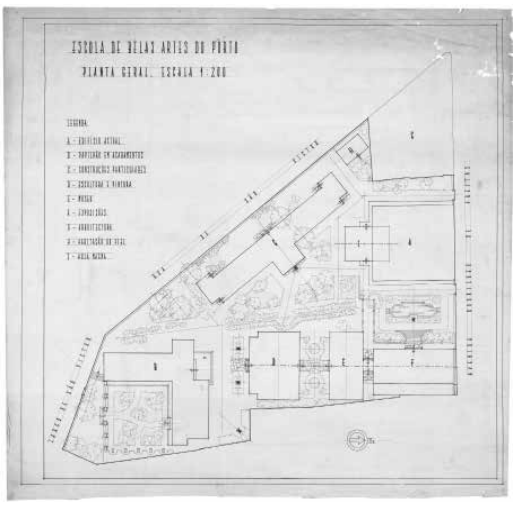

9. Plano para a Escola de Belas-Artes do Porto, Planta Geral, s.a. [Carlos Ramos], s.d. [1949]. Arquivo CDUA-FAUP, BA-40.

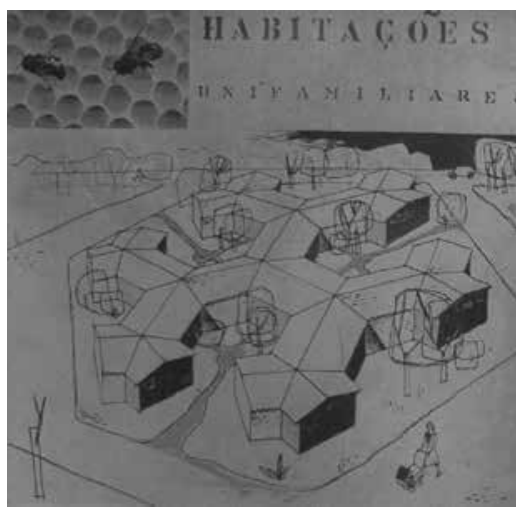

10. Luís Cunha, Fernando Seara, Villares Braga, "Habitações unifamiliares", $4^{\circ}$ ano, Composição, EBAP, 1952-53, Professor Carlos Ramos e Assistente Fernando Távora. ESBAP (1954). Arte Portuguesa, 2-3, 17.
É neste espaço físico e temporal, que se forma Fernando Távora como aluno, entre 1940 e 1950 e como professor, entre 1950 e 1962, momento em que defende a sua tese Da Organização do Espaço. Em 1945, conclui o curso especial e tem consciência do processo de transformação que se vive na Escola e na própria sociedade. Nesse momento, escreve "O Problema da Casa Portuguesa" e "Primitivismo", onde questiona o problema do clássico, do moderno e do popular, antecipando a terceira via, que irá promover a partir dos anos 50. Sobre a sua formação, Távora dirá:

\section{“(...) era um ensino onde até certo ponto a modernidade era} encarada do ponto de vista estilístico. Não era um ensino moderno, mas sim um ensino onde na concepção de certos edifícios se podia utilizar aquilo a que se chamava o estilo moderno".

(Távora, 1971, p.151)

Nos primeiros anos como assistente de Ramos, Távora irá reforçar a importância da teoria, abrindo a disciplina do $4 .{ }^{\circ}$ ano, Composição de Arquitectura, aos debates que ia assimilando nas suas participações no CIAM ou na UIA. Paralelamente empenha-se também no Centro de Estudos de Arquitectura, criado por Ramos, e antecipa o Inquérito à Arquitectura Popular, realizando um "Inquérito às expressões e técnicas tradicionais portuguesas", no ano de 1953. É também neste ano que escreve sobre Arquitectura no jornal O Comércio do Porto onde desenvolve uma outra leitura sobre a Cidade e Arquitectura Moderna do Porto (Távora, 1953).

Assim, mais do que uma formação artística, Fernando Távora herdou uma capacidade de pensar, um método e não informação, como diria Gropius (1950), e uma ética, fixada na expressão de Ramos, "máxima liberdade, máxima responsabilidade" (Távora, 1987, p.75). Sobre esta posição ética, Carlos Ramos defendia um "ensino livre" através de uma formação eclética, "não indicando ou impondo qualquer deles como sendo, o único caminho que conduz à verdade, só assim se assegura da certeza de impedir que qualquer aluno seu deixe, um belo dia, de nos dizer algo de novo" (Ramos, 1953).

Em Lisboa, o processo é distinto, mas igualmente rico. Como referimos, o ensino Beaux-Arts consolida-se na década de $30 \mathrm{com}$ a orientação de Cristino da Silva na cadeira de Arquitectura, mas também com a entrada de Luís Alexandre Cunha em 1935 para a cadeira de Construção e logo no ano seguinte para director da Escola.

Os primeiros sinais de transformação ocorreram, em 1945, com o debate sobre a contratação dos professores de Urbanismo, que levou Cristino da Silva a tomar posições que poderiam ter aberto o ensino na Escola, ao sugerir o convite a urbanistas, como De Groer, Cesar Cort, Keil do Amaral e Faria da Costa. No entanto, deste debate resulta a entrada de Paulino Montez e de Carlos Ramos, que abandonaria a sua posição dois anos mais tarde, em 1948, para regressar ao Porto. 
Paulino Montez torna-se não só o unico professor de Urbanismo como também é nomeado sub-director da Escola ainda no mesmo ano e director em 1949.

Nesta data, tanto Paulino como Cristino da Silva participam na Subcomissão de Reforma do Ensino, comprometendo-se com o espírito moderno da sua redação. Paulino irá convidar para assistentes Alberto Pessoa e Eduard Read Teixeira alargando as perspectivas dentro das cadeiras de Urbanismo. Cristino irá lançar trabalhos de grupo e participar em concursos internacionais, tornando os enunciados mais próximos dos problemas reais e do debate moderno e contando, a partir de 1955, com o apoio de Alberto Pessoa, com que trabalha em Coimbra na Comissão das Obras da Universidade.

Nuno Teotónio Pereira reconhece estas transformações e refere que "Mestre Cristino foi perdendo as suas certezas" (Teotónio, 1998, p.141), abandonando a atitude autoritária com que tinha orientado a cadeira de Arquitectura, especialmente depois da visita a Lisboa de Albert Speer no âmbito da Exposição Moderna Arquitectura Alemã (1941). Manuel Tainha, colega de Teotónio Pereira, frequenta a EBAL neste período marcado pela proximidade de Cristino da Silva não só com os métodos Beaux-Arts, mas também com a cultura nacionalista. O nacionalismo clássico marca os projectos dos seus alunos, por exemplo, para "Um Instituto Oceanográfico", enquanto Alexandre Cunha exigia o clássico na disciplina de Desenho. Nesta situação, Nuno Teotónio Pereira e outros colegas, transferem-se para a EBAP com o objectivo de encontrar uma formação moderna.

Estas iniciativas pontuais são condicionadas pelo autoritarismo do director e pelo adiamento sucessivo do regulamento da Reforma de 1950, que só entrará em vigor em 1957. Neste sete anos, alguns alunos, como Raul Hestnes Ferreira pedem também transferência para o Porto ${ }^{3}$, em direcção a uma escola mais democrática. Outros alunos acreditam que o ensino pode mudar e iniciam uma actividade associativa que reivindica, através das Exposições de Extra-Escolares e principalmente através da revista VER, um "ensino vivo" (Portas, 1954, p.4) e "uma educação experimental", por oposição "educação individualista" (Pacheco, 1957).

O debate sobre as instalações da ESBAL reflecte também a transformação da orientação pedagógica propondo-se primeiro a localização do futuro edifício da Escola no parque de Monsanto (1949), depois realizam-se propostas para a requalificação do colégio de S. Francisco (anos 50) e, por fim, lança-se o concurso para o edifício da ESBAL na Cidade Universitária (1959). Estas propostas serão também adiadas, mas a Escola de Lisboa dava os primeiros sinais de mudança, principalmente pelo desenvolvimente de uma forte consciência crítica dos seus alunos, como Nuno Portas ou José Pacheco.

Podemos assim concluir, que o Congresso de 48, a Sub Comissão de Reforma de 1949 e a Reforma de 1950 possibilitaram uma implementação relativa do Ensino Moderno, quer no Porto, quer em Lisboa, ainda que com dimensões e enquadramentos distintos.

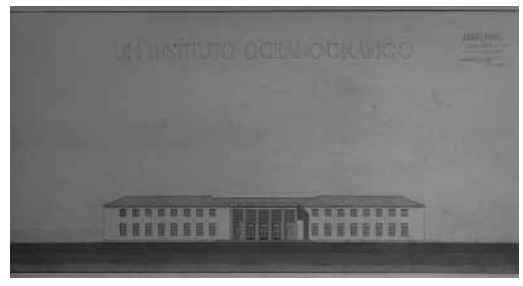

11. Manuel Tainha, "Um Instituto Oceanográfico", Alçado, Composição, EBAL, 1944-45. Arquivo MT.

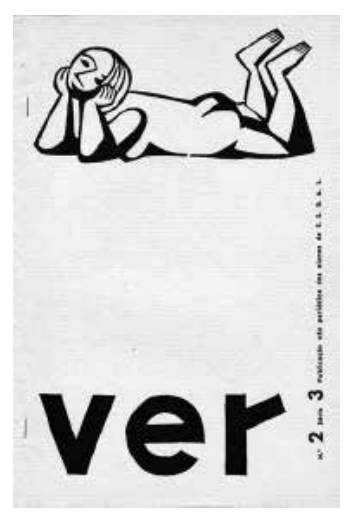

12. Ver, 2 (3), 1957, capa. 

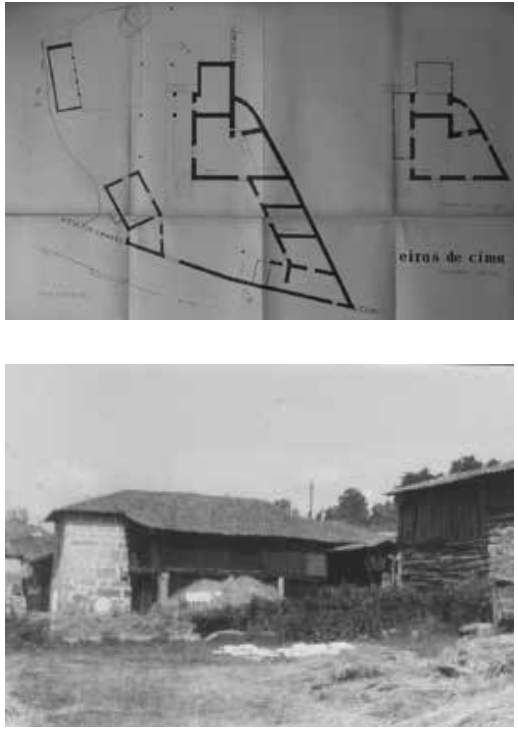

13. Alexandre Alves Costa, "Instalações Agrícolas". Composição de Arquitectura 2, ESBAP, 1961-62, Professor Fernando Távora. Arquivo AAC.
Se no Porto foi possível construir uma escola moderna e democrática, em Lisboa apenas foram desenvolvidas práticas de ensino-aprendizagem modernas no contexto de uma escola autoritária.

\section{O ensino universitário e o currículo científico}

O Regulamento do Ensino Artísitco de 1957 (Reforma de 57) decorre do debate sobre o ensino moderno. Porém, a luta pela nova reforma, que envolveu as escolas e os arquitectos, iria dar origem à contra a reforma, que fixava um currículo moderno, de matriz anglo-saxonica e científica, próximo do sistema universitário. Na verdade, a Reforma de 57 foi o alibi de outras lutas: a luta pela qualificação dos professores; a luta pelas condições contratuais dos professores; a luta pela liberdade associativa dos estudantes; a luta política pela democratização do ensino. De facto, o despontar da acção social e política do Arquitecto, depois de 1958 e principalmente depois de 1961, tornou a formação técnica proposta pela reforma em algo "requentado", como referiu Keil do Amaral (1958, p. 43).

De um modo geral, nas duas escolas, directores, professores e alunos viram na Reforma de 57 uma oportunidade, não só pelo currículo, mas principalmente pela possibilidade de contratar assistentes para todas os grupos científicos e pela capacidade de se organizarem centros de estudos e cursos de aperfeiçoamento. No entanto, a aproximação a um sistema universitário em crise levantou também um conjunto de críticas que se avolumaram ao longo da década de sessenta com a crítica à própria universidade. As críticas tiveram assim diferentes focos: o sumatório de disciplinas proposto no currículo, o funcionamento das aulas "científicas" nas faculdades de ciências, os critérios de contratação de docentes e a dificuldade de criar os centros de estudos. Contudo, foi possível observar que um conjunto significativo de assistentes procurou construir uma proposta pedagógica actualizada de acordo com o debate internacional que se desenrolava na UIA, nO TEAM 10 e nas escolas italianas, brasileiras e inglesas.

Neste sentido, a hierarquização das disciplinas proposta pelo currículo foi subvertida por um conjunto de experiências pedagógicas, procurando conciliar a formação artística e técnica do arquitecto com a formação social, onde a cidade se tornou a principal procupação pedagógica. Estas experiências pressuponham também novos métodos de projecto onde a análise e a crítica deveria complementar a síntese, afastando o "arquitecto-lápis-maravilhoso"4, como reivindicavam Lixa Filgueiras e Arnaldo Araújo e também os "práticos", como reclamava Fernando Távora (1970). Tratava-se, como referia Nuno Portas, em 1963, de estudar o "Problema-humano-que-carece-de-arquitectura" (Portas, 2005, p. 405).

Alexandre Alves Costa entra na Escola em 1956 e no ano seguinte adere à "Reforma de Carlos Ramos". Acompanha a sua implementação, usufruindo das propostas de Fernando Távora para a Teoria e História da Arquitectura e para a Composição de Arquitectura e acompanha 
também a contestação à reforma, especialmente na luta pela autonomia universitária de 1962, sendo um dos dinamizadores do jornal ESBAP 1. No último ano do curso, realiza o estágio no LNEC, sob orientação de Filgueiras e de Nuno Portas. Assim, se com Távora aprendeu a integrar a História no processo de projecto, com Portas e Filgueiras adquire instrumentos de investigação sobre o projecto; ambos irão convergir para uma futura prática pedagógica na Escola do Porto e posteriormente na Escola de Coimbra.

O percurso de Domingos Tavares no Porto é interrompido por uma curta experiência na ESBAL. As escolas já não são espaços antagónicos antevendo inclusive experiências de ensino comuns, como a realizada por Siza no ano de 1965-66 sob o "método de Nuno Portas". Como explica nos seus texto "Memórias" (Tavares, 2012), a aprendizagem é feita a partir da relação pessoal com os mestres: Távora, Siza, Portas, Gigante e Viana de Lima.

Em Lisboa, Gonçalo Byrne e Mário Krüger acompanham a formação centrada nos métodos de projecto, personificada por Nuno Portas e a sua equipa de assistentes, Francisco Silva Dias, Bartolomeu Costa Cabral e Carlos Manuel Ramos. Os seus relatórios de estágios ${ }^{5}$ abordam exactamente este problema, que Kruger irá perseguir nos seus estudos em Cambridge e na Bartlett. Estes dois exemplos são bem significativos da importância do relatório de estágio na formação do Arquitecto, que substitui a antiga CODA, porque constitui, na sua maioria, uma reflexão teórica a partir da experiência de projecto, privilegiando o projecto como instrumento de investigação.

$\mathrm{Na}$ década de 60, são concluídas as obras na ESBAP com a inauguração da Aula Magna e com a reabilitação do palacete, mas em Lisboa continua por resolver a construção de um novo edifício. Anulado o concurso de 1958, Carlos Ramos e Manuel Tainha são convidados a desenvolver o projecto do novo edifício da Escola de Lisboa, a construir na Cidade Universitária. Nas três versões que apresentam entre 1959 e 1966 pretende-se, através de uma mega-estrutura, aproximar as Artes da Universidade.

É também neste período que, nas duas Escolas, os polémicos concursos para professor obrigam os candidatos a conciliar as provas práticas com provas teóricas, contribuindo também para um novo perfil do professor, o professor investigador. Deste conjunto de teses saíram aliás trabalhos de referência como "Da organização do Espaço" de Fernando Távora (ESBAP, 1962) ou "A Arquitectura para Hoje" de Nuno Portas (ESBAL, 1964).

A substituição dos mestres (Cristino da Silva, Paulino Montez, Carlos Ramos e Rogério de Azevedo), devido ao seu jubileu, por jovens assistentes vai transformar a contestação à Reforma de 57 numa crise do sistema de ensino. Os anos de 1968 e 1969 marcarão no Porto e em Lisboa o início do fim da Reforma de 57 e a abertura de um processo experimental e algo revolucionário que só terminará no 25 de Abril de 1974.

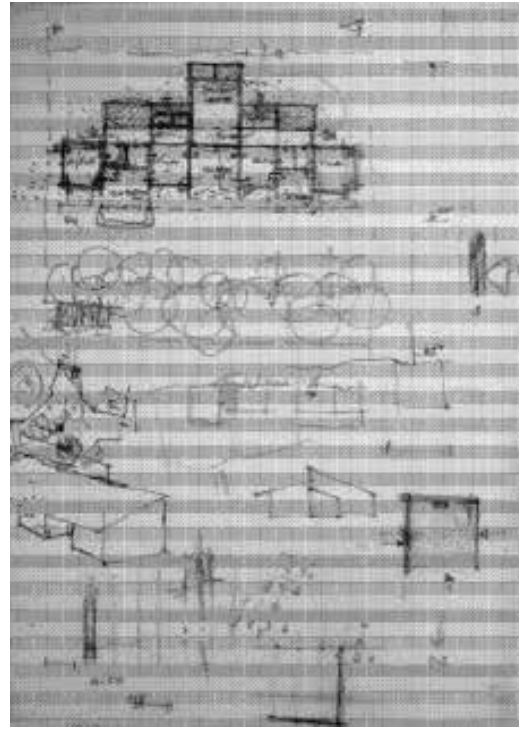

14. Domingos Tavares, "Escola primária de 4 salas", Composição de Arquitectura 1, ESBAL, 1966-67, Professor Sebastião Formosinho

Sanchez. Arquivo DT.

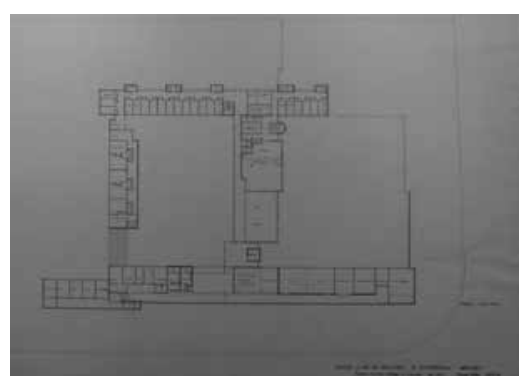

15. Domingos Tavares, "Escola e Lar de Alunas de Enfermagem em Bragança, ESBAP, 1971-72, Professor Viana de Lima. Arquivo DT.

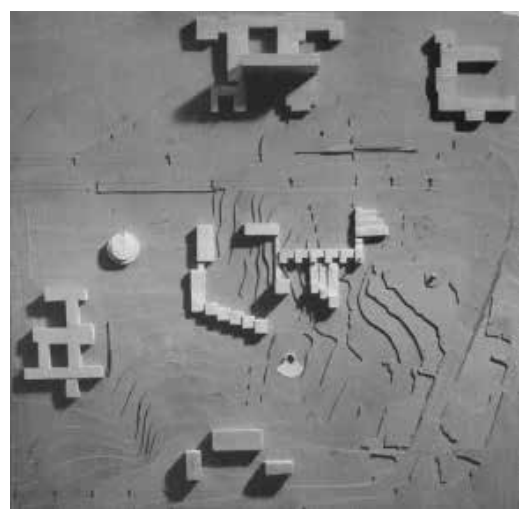

16. Manuel Tainha, Carlos Ramos, "Escola Superior de Belas-Artes de Lisboa", $1 .^{\circ}$ Estudo Prévio, 1959-01-15. Arquivo MT 


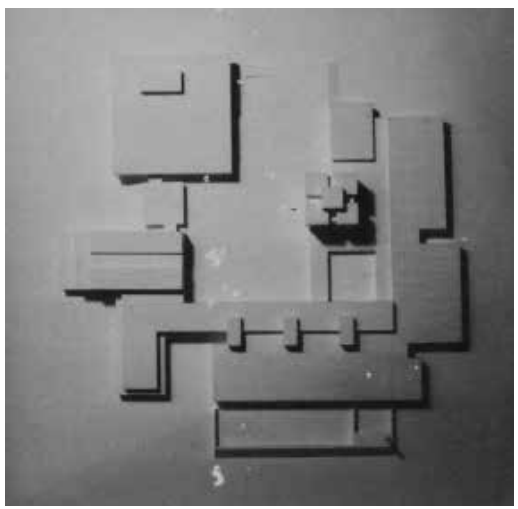

17. Tainha, Carlos Ramos, Projecto da Escola Superior de Belas-Artes de Lisboa, $2 .^{\circ}$ Estudo Prévio, Manuel 1960-03-24. Arquivo MT

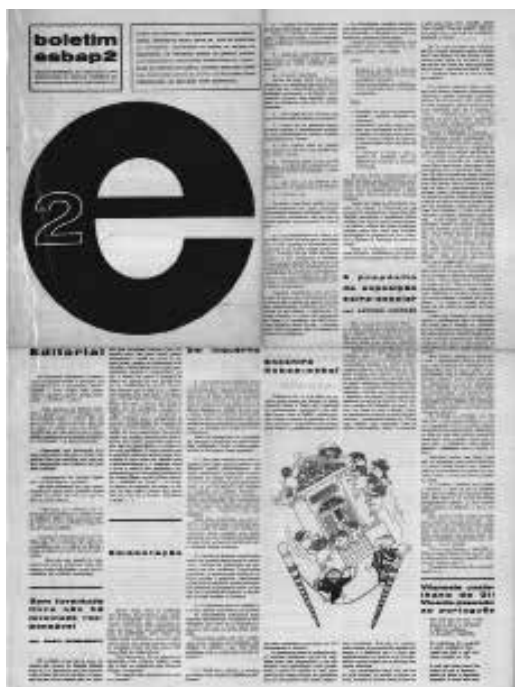

18. ESBAP (1968), 2.

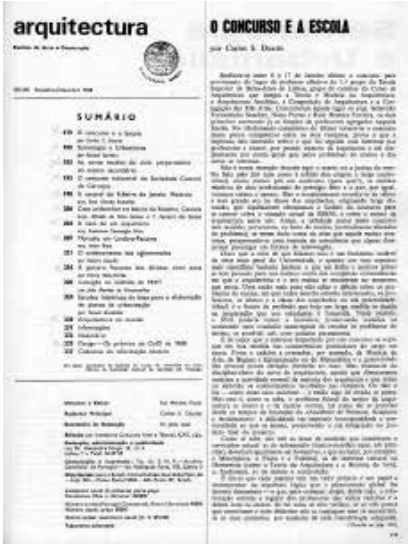

19. Duarte, C. S. (1968). O Concurso e a Escola. Arquitectura. 105-106, editorial.
Em 1970, as duas escolas iniciam experiências pedagógicas onde Távora integrará a Comissão Coordenadora do Regime Experimental e Raul Hestnes Ferreira será chamado ao ensino em Lisboa por Frederico George para apoiar uma experiência de coordenação horizontal. Estas experiências reivindicam a autonomia disciplinar da Arquitectura e um modelo de gestão partilhado entre professores e alunos. $\bigcirc$ corpo docente será amplamente renovado neste período garantindo, com dificuldades, a transição para a Democracia e para a integração na Universidade, decretada em 1979. No Porto entram dois jovens assistentes, Alexandre Alves Costa, em 1972, e Domingos Tavares, em 1973, que dinamizarão o debate interno na Escola e apoiarão as experiências colectivas, como o SAAL e as Bases Gerais. Em Lisboa, o processo será mais conturbado, com a demissão de Nuno Portas e Raul Hestnes, entre outros, e com a orientação da Escola entregue a Augusto Brandão e Tomás Taveira.

\section{O Legado do Ensino Moderno}

O ensino moderno não corresponde a um modelo fechado e rígido, mas sim a uma atitude perante o processo de ensino aprendizagem que genericamente defenimos de experimental, democrático e humanista. Neste sentido podemos observar três fases distintas de construção, fixação e implementação deste paradigma nos dois cursos de Arquitectura, onde a Reforma de 57 constitui o momento de fixação.

Estas fases decorrem de um processo de reacção dos novos professores e dos alunos aos modelos e métodos de ensino propostos nas reformas, promovendo processos de ensino-aprendizagem críticos do paradigma vigente. Assim esta reacção dá origem a dois paradoxos: por um lado a implementação de um Ensino Moderno num Currículo Beaux-Arts e, por outro lado, o desenvolvimento de um Ensino Experimental ou Social num Currículo Moderno.

Curiosamente os processos de reforma do ensino da Arquitectura, tanto o de 1931-32, como o de 1950-57, foram consensuais e corresponderam às ambições dos professores, dos arquitectos e dos políticos. $\bigcirc$ que não foi consensual foi a sua implementação. Podemos assim afirmar que o processo de transformação do ensino Beaux-Arts em ensino Moderno pode observar-se nas duas escolas, assim como a crítica ao currículo moderno. Se quisermos fixar algumas datas, podemos considerar que 1949 é o ano do ensino moderno, reivindicado no Congresso do ano anterior e adoptado por todos os professores no relatório da Subcomissão da Reforma do Ensino Artístico. E também que entre 1950 e 1957, num momento de grande ambiguidade legislativa, o ensino moderno encontra espaço para uma integração expressiva nos dois cursos de arquitectura, tendo grande impacto ao nível das dinâmicas culturais. Podemos ainda verificar que entre 1958 e 1969 a implementação do currículo moderno deu origem a um processo de experimentação pedagógica, o que não deixa de ser uma atitude moderna, procurando a sua permanente renovação. Ainda quanto à 
cronologia, o ano de 1969 marca a falência do currículo moderno de 1957, ainda que ele tenha perdurado até ao final dos anos 70, mas já sem constituir um projecto de ensino.

De facto, a Reforma de 57 colidiu com três factores: factores de ordem pedagógica, porque a reforma não previu estratégias de coordenação que integrassem os conhecimentos sectorizados no projecto; factores de ordem cultural, porque os arquitectos começaram a recusar a perspectiva tecnocrática e a valorizar a perspectiva humanista, integrando a ciade e a história, por exemplo o Inquérito, factores de ordem política com a crítica ao Estado Novo, devido ao episódio Humberto Delgado e ao início da guerra colonial, entre outros.

O ensino moderno transformou definitivamente os cursos de arquitectura, quer nos conteúdos, integrando o triângulo cidade-história-homem no triângulo forma-programa-construção, quer no perfil dos professores, permanecendo o professor-profissional, mas acolhendo também o professor-investigador, e ainda fixou questões intemporais, como a coordenação, a experimentação, a liberdade e a tradição humanista.

Estes aspectos ou valores estão de algum modo presentes no curso de Coimbra, devido em parte à presença dos professores do Porto e Lisboa no processo de construção do curso e também devido ao contexto universitário, que obriga a um permanente diálogo com as disciplinas complementares. A formação deste conjunto de professores no âmbito da Reforma de 57, ainda que sob uma forte consciência crítica (Costa, 1982; Tavares, 1982), terá com certeza permitido construir em Coimbra um curso que procura concliar as Artes e as Ciências, o projecto e a teoria, valorizando a própria cidade como espaço privilegiado de aprendizagem.

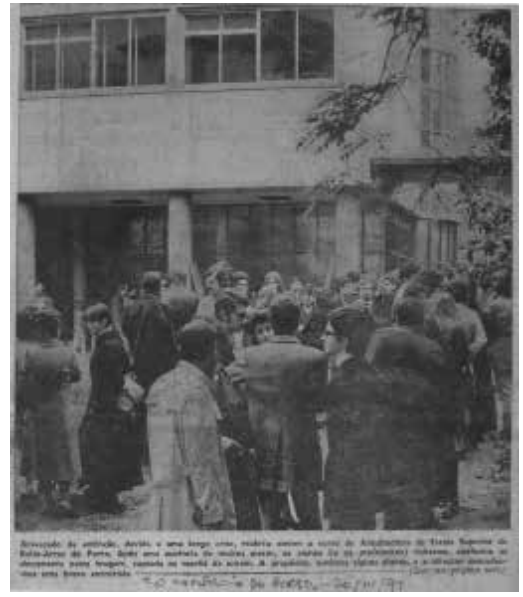

20. Comércio do Porto (1971). "...reabriu o curso de Arquitectura..."

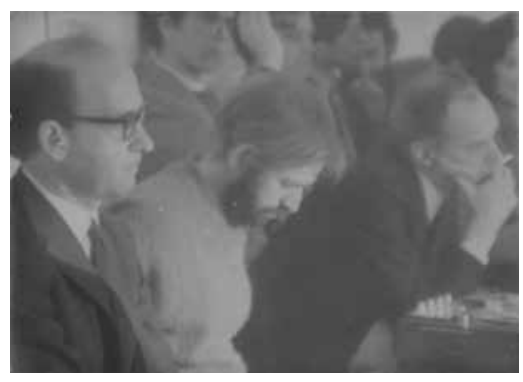

21. ESBAL, Avaliações, Sebastião Formosinho Sanchez, Raul Hestnes Ferreira, Francisco Pereira de Moura (Economista), Maio 1971. Arquivo RHF.

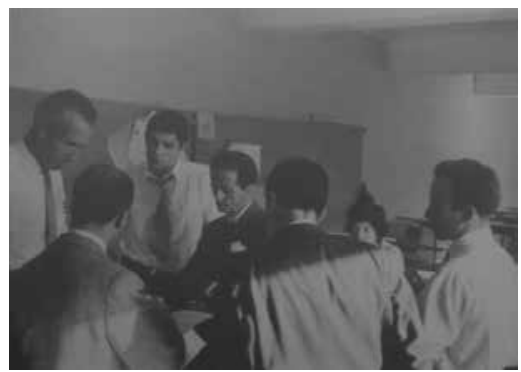

22. Carlos Ramos e os seus alunos na ESBAP, 1958. Arquivo FCG. 
$1 \rightarrow 0$ Curso de Arquitectura da Faculdade de Ciências e Tecnologia da Universidade

de Coimbra é criado em 1988. Sobre este assunto ver o texto nesta revista

de Alexandre Alves Costa.

$2 \rightarrow$ Luís Cristino da Silva, Carlos Ramos, Paulino Montez e Cassiano Branco.

$3 \rightarrow$ Raul Hestnes Ferreira é expulso da Escola de Lisboa na sequência

de manifestações pela Paz.

$4 \rightarrow$ Esta expressão é utilizada numa carta de Arnaldo Araújo a Octávio Lixa

Filgueiras, datada de 5 de Outubro de 1964 (espólio O. Lixa Filgueiras).

$5 \rightarrow$ Krüger, M. J. T. (1972), Planeamento e construção de edifícios

universitários. Lisboa: Esbal. (Relatório de Estágio). Byrne, G (1969).

Método de Arquitectura. Arquitectura, 109, p.127-130.

\section{Bibliografia}

Costa, A. A. (2012). Primeira Anotação do Curso de Arquitectura de Coimbra. Joelho, 3, 16-26.

-

Costa, A. A. (1982). Dissertação ... Porto: Edições do Curso de Arquitectura da ESBAP.

Dewey, J. (1959), Democracia e Educação. São Paulo: Companhia Editora Nacional.

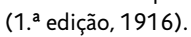

-

Gropius, W (1939), Training the Architect. Twice a Year, 2, 42-151.

-

Gropius, W (1950), Blueprint for an architect's training. L'Architecture d'aujoud'hui, 28, 69-74. (Trad. Port. Carlos Ramos, Plano para um ensino da arquitectura)

Gropius, W (1951), In search of a better architectural education. In Giedion, S. CIAM. A decade of new architecture (pp.41-46). Editions Girsberger.

Gropius, W. (1951). Mensagem de Walter Gropius ao Congresso. Tópicos para a discussão sobre o ensino da arquitectura. Arquitectura, 40, 14-15.

Keil do Amaral, F. (1958). A reforma do ensino de Belas-Artes. Arquitectura, 63, 43.
Moniz, G. C. (2011). O Ensino Moderno da Arquitectura. A Reforma de 57 e as Escolas de Belas Artes em Portugal (1931-69). Tese de doutoramento apresentada na Universidade de Coimbra.

Pacheco, J. (1957). Ensino da Arquitectura 2 Ver, 2 (3).

Portas, N. (1954). O Drama da Cultura na Escola. Ver, 3 (1), 4-7.

Portas, N. (2005). Ensino da Arquitectura. Uma experiência pedagógica na ESBA do Porto. In Mendes, M. (Org.). Arquitectura(s): História e crítica, Ensino e Profissão (pp.402-405). Porto: FAUP Publicações. [1 ${ }^{\mathrm{a}}$ ed., 1963]

Ramos, C. (1935). Arquitectura. Algumas Palavras e o seu Verdadeiro Significado. Memória Elucidativa e Justificativa de Um Palácio da Academia Nacional de Belas Artes, Prova do Concurso para o lugar da 4. ${ }^{\mathrm{a}}$ cadeira de Professor da Escola de Belas-Artes de Lisboa, 24 de Agosto de 1933. Sudoeste, 3, 36-37.

Ramos, C. (1935). Palestra dedicada a todos os alunos da Escola de Belas-Artes de Lisboa. [manuscrito].
Ramos, C. (1953). In ESBAP, II Exposição Magna. Porto.

Subcomissão de Arquitectura (1949), Relatório da Subcomissão de Arquitectura. Reforma do Ensino das Belas-Artes. Arquivo FCG, Espólio LCS.

Tavares, A. R. G. (1933), Ensino Clássico Ensino Moderno?. Labor, 45

Tavares, D. (1982). Da Formosa à Firmeza. Porto: Edições do Curso de Arquitectura da ESBAP.

-

Távora, F. (1971), Entrevista com o Arquitecto Fernando Távora, Arquitectura, 123, 150-154.

Távora, F. (1987), Evocando Carlos Ramos $R A, 0,75$.

Pereira, N. T. (1998). Cristino, mestre de uma geração rebelde. In Fernandes, J. M. (coord.), Luís Cristino da Silva [Arquitecto] (p.141). Lisboa: FCG. 